\title{
Difference of the hemodynamic changes induced by tracheal intubation using remifentanil between smokers and nonsmokers
}

\author{
Sang Hoon Sung, Soo Bong Yu, Doo Sik Kim, Kyung Han Kim, Tae Ho Jang, Se Hwan Kim, and Sie \\ Jeong Ryu
}

Department of Anesthesiology and Pain Medicine, Kosin University College of Medicine, Busan, Korea

Background: It was well-known that smoking affects the cardiovascular system, and remifentanil can suppress the sympathetic stimulations induced by tracheal intubation. The purpose of this study was to investigate whether there was any difference in the hemodynamic changes induced by tracheal intubation with using remifentanil between smokers and nonsmokers.

Methods: Eighty patients were enrolled: male smokers (MS), male nonsmokers (MN), female smokers (FS) and female nonsmokers (FN). Anesthesia was induced with diluted remifentanil $(20 \mu \mathrm{g} / \mathrm{ml})$ at a rate of $10 \mu \mathrm{g} / \mathrm{kg} / \mathrm{hr}$ using an infusion pump, and $2 \mathrm{~min}$ later, midazolam $0.05 \mathrm{mg} / \mathrm{kg}$ and propofol $0.8 \mathrm{mg} / \mathrm{kg}$ were injected for achieving unconsciousness. Rocuronium $1 \mathrm{mg} / \mathrm{kg}$ was used for muscle relaxation, and tracheal intubation was performed $2 \mathrm{~min}$ after rocuronium injection. After tracheal intubation, the remifentanil was decreased to $2 \mu \mathrm{g} / \mathrm{kg} / \mathrm{hr}$. The mean arterial pressure (MAP) and heart rate (HR) were checked before induction, on unconsciousness, just before intubation, just after intubation and 1, 2 and 3 minutes after intubation, and these values were compared between the groups.

Results: In men, the MAP and HR just after intubation and at 1, 2 and 3 minutes after intubation in Group MS were significantly higher than those of Group MN $(\mathrm{P}<0.05)$. For the women, the HR in both groups (the FS and FN groups) were increased just after intubation and 1, 2 and 3 minutes after intubation compared with that at the baseline, respectively, but there was no difference between the two groups.

Conclusions: There was a difference of the hemodynamic changes induced by tracheal intubation with using remifentanil between the male smokers and nonsmokers, but not in women. (Korean J Anesthesiol 2010; 58: 508-513)

Key Words: Hemodynamic change, Intubation, Nonsmoker, Remifentanil, Smoker.

\footnotetext{
Received: February 3, 2010. Revised: 1st, February 24, 2010; 2nd, March 26, 2010. Accepted: April 13, 2010.

Corresponding author: Sie Jeong Ryu, M.D., Department of Anesthesiology and Pain Medicine, Kosin University College of Medicine, 34, Amnam-dong, Seo-gu, Busan 602-030, Korea. Tel: 82-51-990-6265, Fax: 82-51-254-2504, E-mail: siejeong@ns.kosinmed.or.kr Presented at the 86th Annual Scientific Meeting of the Korean Society of Anesthesiologists, Jeju, November 6-7, 2009.

(c) This is an open-access article distributed under the terms of the Creative Commons Attribution Non-Commercial License (http:// creativecommons.org/licenses/by-nc/3.0/), which permits unrestricted non-commercial use, distribution, and reproduction in any medium, provided the original work is properly cited.
} 


\section{Introduction}

The recent developments in intravenous anesthetics have allowed intravenous anesthetics to move from being complimentary to becoming the main anesthetics during surgery. Propofol and remifentanil's context-sensitive half times are short. So, in the setting of total intravenous anesthesia, even when the anesthesia is performed over a long period of time, the recovery time is quite short compared to that of inhalational anesthetics [1]. Remifentanil is an opioid with one of the shortest context-sensitive half times. During endotracheal intubation, it inhibits the activation of the sympathetic nervous system and prevents increases of the blood pressure and heart rate. Much research has been done on the optimal dose for these effects [2]. There are many reports of clinical situations where certain dosage amounts of remifentanil suppressed the hemodynamic and cardiovascular responses from endotracheal intubation in hypertensive patients [3], elderly patients [4] and diabetic patients [5].

Smokers are known to have an extremely increased cardiovascular response compared to that of nonsmokers [6,7]. Yet, there have hardly been any reports on the appropriate dosages of remifentanil for smokers and nonsmokers to repress the cardiovascular response to endotracheal intubation. For smokers, endotracheal intubation increases the myocardial oxygen demand, but it constricts the coronary artery, which elevates vascular resistance and reduces the blood flow rate [8]. So preventing the hemodynamic changes due to endotracheal intubation is very important. We attempted to determine if there is a difference between smokers and nonsmokers for their cardiovascular response to remifentanil that is administered for endotracheal intubation.

\section{Materials and Methods}

Eighty ASA I \& II patients of both genders and whose ages were between 30 and 60 and the BMI ranged from 20 to 30 were enrolled in the study. In each gender group, there were 20 smokers and 20 nonsmokers. The gender groups were divided into male smokers (Group MS), male nonsmokers (Group MN), female smokers (Group FS) and female nonsmokers (Group $\mathrm{FN}$ ), resulting in 4 subgroups. After the approval of the local ethics committee, the authors conducted a preanesthetic visit with the patients. The patients gave us their written informed consent after they were told of the purpose and methodology of the research.

During the preanesthetic visit before surgery, the authors made inquiries about whether or not the patients were smokers. If they had a history of smoking for 2 or more years and they still smoked, then they were placed in the smoking group. The duration of smoking (in months) and the quantity of smoking (number of cigarettes per day) were recorded and we recommended that patients should stop smoking after the preanesthetic visit. If the patient had never smoked, then they were put in the nonsmoking group. Patients were excluded if they had hypertension, diabetes mellitus, neurological disorders or a past history of taking cardiovascular drugs such as beta blockers. Patients were excluded if they were expected to have difficult intubation or if they did not have successful endotracheal intubation on the first try.

As premedication, 30 minutes before the surgery, intramuscular injection was done with ranitidine (Urantac ${ }^{\circledR}$, Whanin, Korea) 25 mg and midazolam (Dormicum ${ }^{\circledR}$, Roche, Switzerland) $2.5 \mathrm{mg}$. The patients were monitored during anesthetic induction with electrocardiography, noninvasive blood pressure measurement and a pulse oxymeter. Lactated Ringer' solution was administered as intravenous fluid with an $18 \mathrm{G}$ angio needle in a forearm vein. For prehydration, $1 / 2$ of the calculated maintenance volume $(2 \mathrm{ml} / \mathrm{kg} / \mathrm{hr})$, with considering the NPO time, was infused before induction. Induction of anesthesia was done according to the methodology of Shim et al. [2] as follows. Remifentanil (Ultiva $^{\mathrm{TM}}$, GSK, Italy) $1 \mathrm{mg}$ was diluted with $50 \mathrm{ml}$ of normal saline $(20 \mu \mathrm{g} / \mathrm{ml})$, and then using an infusion pump (Pilot C, Fresenius Vial, France), continuous infusion was started at a rating of $10 \mu \mathrm{g} / \mathrm{kg} / \mathrm{hr}$ concomitant with administering $6 \mathrm{~L} /$ min oxygen with a face mask for 2 minutes. Two minutes after remifentanil infusion, midazolam $0.05 \mathrm{mg} / \mathrm{kg}$ and propofol (Provive $^{\mathrm{TM}}$, Claris, India) $0.8 \mathrm{mg} / \mathrm{kg}$ were administered by intravenous injection to induce unconsciousness. If the patient did not lose consciousness within 1 minute, then propofol 20 mg was additionally administered. The loss of consciousness was checked by the eyelash reflex. Rocuronium (Esmeron ${ }^{\circledR}$, Organon, Netherlands) $1 \mathrm{mg} / \mathrm{kg}$ was intravenously injected over a period of 10 seconds. After controlled ventilation for 2 minutes, endotracheal intubation was performed. Afterwards, the remifentanil infusion was reduced to $2 \mu \mathrm{g} / \mathrm{kg} / \mathrm{hr}$. With the control mode ventilation, anesthesia was maintained with sevoflurane $1.5 \%$ in $\mathrm{O}_{2}$ : Air $=1.5 \mathrm{~L}: 2.5 \mathrm{~L} / \mathrm{min}$, with a tidal volume of $10 \mathrm{ml} / \mathrm{kg}$ and a respiratory rate of $10 \mathrm{bpm}$.

The measurements of the mean arterial pressure (MAP) and heart rate (HR) were done before anesthetic induction (baseline), at the time of just falling unconsciousness, just before endotracheal intubation, just after intubation and 1, 2 and 3 minutes after intubation. During anesthetic induction, when the systolic blood pressure fell below $80 \mathrm{mmHg}$, the administration of remifentanil was stopped.

All the measurements are shown as the mean \pm standard deviation. SPSS 17.0 (SPSS, Inc., Chicago, IL) was used for statistical analysis. The height, weight and the dosage of remifentanil and the total amount of infused propofol were 
compared using the Student t-test. The comparisons of heart rates and the MAP between the groups were done using the independent t-test. The changes over time of the heart rates and MAPs within the groups were compared using repeated measures of ANOVA test. $P$ values $<0.05$ were considered to be significant.

\section{Results}

There was no significant difference between the male smokers and nonsmokers and between female smokers and nonsmokers for age, weight, height, the administered remifentanil dose and the propofol dose until endotracheal intubation (Table 1). None of the patients had their remifentanil infusion stopped because none of the patients had a decreased systolic blood pressure below $80 \mathrm{mmHg}$ during anesthetic induction. There was no difference between the smokers and nonsmokers for the baseline MAPs and heart rates. The average duration of smoking for men was 17.1 years and the average amount smoked was 24 cigarettes per day. For women, the average duration of smoking was 12.7 years. They smoked on average 18 cigarettes per day.

In Group MN, there was no difference between the baseline MAP and the MAP just after endotracheal intubation. In Group MS, the MAP just after endotracheal intubation was significantly increased as compared with the baseline MAP $(110.1 \pm 17.3$ mmHg vs $87.9 \pm 4.6 \mathrm{mmHg}$, respectively) and the MAPs were significantly increased at just after endotracheal intubation $(110.1 \pm 17.3 \mathrm{mmHg}$ vs $88.8 \pm 14.6 \mathrm{mmHg}$, respectively) and at 1 , 2 and 3 minutes after intubation, as compared with Group $\mathrm{MN}$, respectively (Fig. 1A, $\mathrm{P}<0.05$ ). In group $\mathrm{MN}$, the heart rate was significantly increased just after endotracheal intubation (72.5 $\pm 11.4 \mathrm{bpm}$ vs $64.1 \pm 3.5 \mathrm{bpm}$, respectively) and 1 and 2 minutes after intubation as compared with the baseline heart rate (Fig. 1B, $\mathrm{P}<0.05)$. In Group MS, the heart rate was significantly increased just after endotracheal intubation (88.5 $\pm 16.5 \mathrm{bpm}$ vs $68.3 \pm 8.74 \mathrm{bpm}$ ) and at 1, 2 and 3 minutes after intubation as compared with baseline, respectively, and these values were higher than those of Group MN (Fig. 1B, P < 0.05).

For women, there was no difference between Group FN and Group FS for the MAP measured just after endotracheal

Table 1. Demographic Data

\begin{tabular}{|c|c|c|c|c|}
\hline & Group MS & Group MN & Group FS & Group FN \\
\hline Age (yr) & $56.3 \pm 9.4$ & $54.2 \pm 8.1$ & $56.5 \pm 10.3$ & $54.7 \pm 9.8$ \\
\hline Weight (kg) & $76.0 \pm 8.6$ & $72.6 \pm 7.1$ & $55.9 \pm 7.1$ & $58.3 \pm 10.2$ \\
\hline Height (cm) & $172.7 \pm 2.6$ & $171.1 \pm 4.6$ & $162.4 \pm 5.6$ & $160.9 \pm 4.6$ \\
\hline Remifentanil dose $(\mu \mathrm{g})$ & $81.6 \pm 11.0$ & $77.4 \pm 13.6$ & $59.0 \pm 8.4$ & $60.6 \pm 10.4$ \\
\hline Propofol dose (mg) & $60.8 \pm 6.9$ & $58.1 \pm 5.7$ & $44.7 \pm 5.7$ & $46.6 \pm 8.0$ \\
\hline Baseline MAP (mmHg) & $87.9 \pm 4.7$ & $90.2 \pm 6.0$ & $87.1 \pm 10.1$ & $86.8 \pm 10.0$ \\
\hline Baseline HR (bpm) & $68.3 \pm 8.7$ & $64.1 \pm 3.5$ & $72.4 \pm 3.9$ & $77.1 \pm 14.8$ \\
\hline
\end{tabular}

Values are expressed as means \pm SDs. There were no differences in the patient characteristics and baseline values between Group MS and Group MN, and between Group FS and Group FN, respectively. Group MS: male smokers, Group MN: male nonsmokers, Group FS: female smokers, Group FN: female nonsmokers, MAP: mean arterial pressure, HR: heart rate.

A

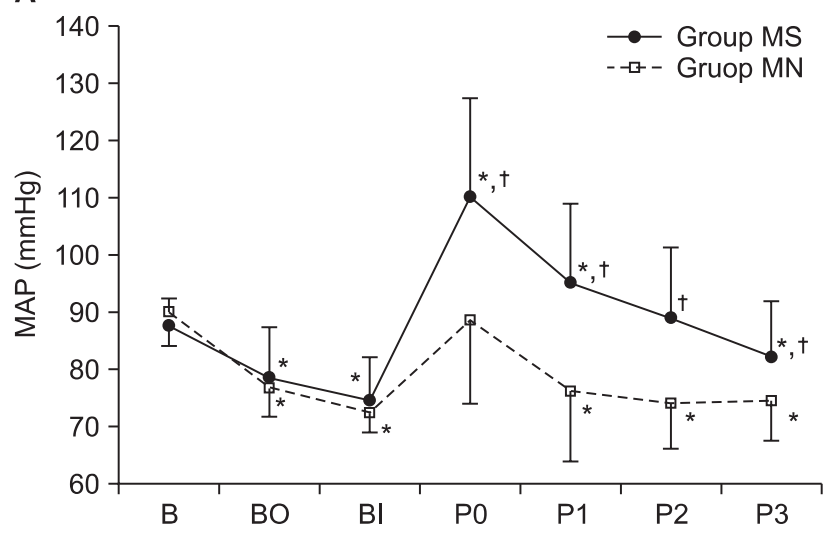

B

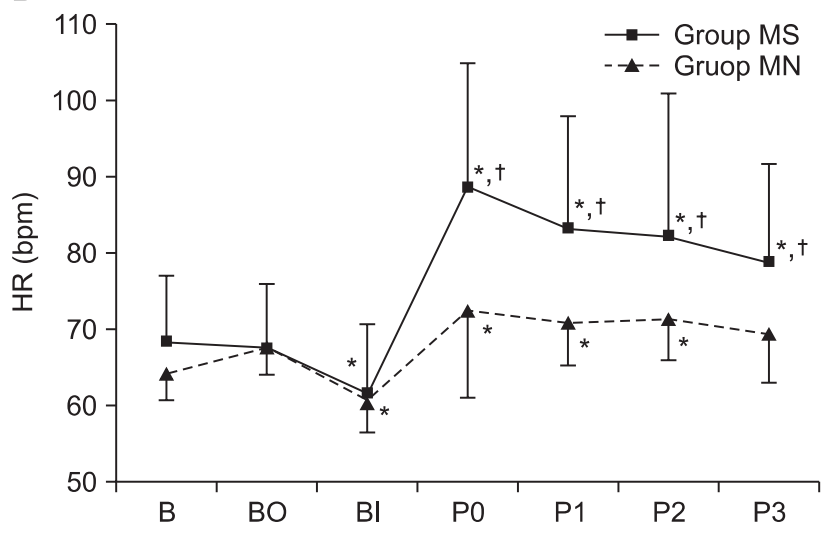

Fig. 1. Changes of the MAP (mean arterial pressure) (A) and HR (heart rate) (B) in the males. The MAP and HR at P0 and 1,2 and 3 minutes in Group MS were higher than those of Group MN, respectively $(\mathrm{P}<0.05)$. In Group MS, the HR was increased at P0 and 1 , 2 and 3 minutes compared with that at baseline. Group MS: male smokers, Group MN: male nonsmokers, B: baseline, BO: on unconsciousness, BI: just before intubation, P0: just after intubation, $\mathrm{P} 1,2,3: 1,2,3$ minutes after intubation. ${ }^{*} \mathrm{P}<0.05$ compared with baseline, ${ }^{\dagger} \mathrm{P}<0.05$ compared with Group $\mathrm{MN}$. 
intubation and 1, 2 and 3 minutes after intubation. In Group $\mathrm{FN}$, the MAP was increased just after endotracheal intubation compared to the baseline MAP $(98.4 \pm 17.3 \mathrm{mmHg}$ vs $86.6 \pm$ $10.0 \mathrm{mmHg}$, respectively) (Fig. $2 \mathrm{~A}, \mathrm{P}<0.05)$. The heart rate in Group FN just after endotracheal intubation was higher than the baseline heart rate $(88.6 \pm 22.8 \mathrm{bpm}$ vs $77.1 \pm 14.8 \mathrm{bpm}$, respectively). It was significantly increased at 1 and 2 minutes after intubation (Fig. 2B, P < 0.05). In Group FS, the heart rate just after intubation was increased higher than that of baseline $(88.9 \pm 10.8 \mathrm{bpm}$ vs $72.4 \pm 3.9 \mathrm{bpm}$, respectively), and it was significantly increased at 1,2 and 3 minutes after intubation (Fig. 2B, $\mathrm{P}<0.05$ ). But there was no difference in the heart rate between Groups FN and FS (Fig. 2B).

\section{Discussion}

Endotracheal intubation is a commonly used, necessary maneuver for securing the airway when inducing general anesthesia. However, endotracheal intubation causes the stimulation of the sympathetic nervous system, which increases the plasma catecholamine level and this can cause an elevated blood pressure and tachycardia [9]. Most myocardial ischemia that occurs during anesthesia is related to endotracheal intubation and especially to tachycardia [10]. So it is important to prevent hemodynamic changes during anesthetic induction.

To minimize such cardiovascular responses, the use of opioids, local anesthetics, inhalational anesthetics, beta adrenergic blockers, calcium channel blockers and other cardiovascular drugs has been shown to be effective [11]. Among them, opioids have been the most widely used drugs. Fentanyl blocks the sympathetic nervous responses during anesthetic induction. The amount of fentanyl used for endotracheal intubation with using a laryngoscope is known to be directly proportional to the ability to suppress the cardiovascular response, so fentanyl has often been used [12], yet remifentanil has recently become more widely used.

There have been many studies on what the appropriate dosage of remifentanil is in order to suppress the hemodynamic response to endotracheal intubation. The methods of administration are a bolus injection, an injection of a loading dose with a continuous infusion, and a continuous infusion. For the induction of anesthesia using propofol and rocuronium, Hall et al. [13] administered a loading dose of remifentanil 0.5 $\mu \mathrm{g} / \mathrm{kg}$ and then they continuously infused $0.25 \mu \mathrm{g} / \mathrm{kg} / \mathrm{min}$. Shim et al. [2] reported that continuously infusing remifentanil at 0.2 $\mu \mathrm{g} / \mathrm{kg} / \mathrm{min}$ effectively suppressed the stimulus-caused increase in blood pressure and heart rate. Their results show that the amount of remifentanil administered until endotracheal intubation was important for inhibiting the hemodynamic response regardless of the method of administration. The optimal dose was normally $1-1.5 \mu \mathrm{g} / \mathrm{kg}$. This current study followed the methodology of the study by Shim et al. [2] by inducing anesthesia for 6-7 minutes until endotracheal intubation. Thus, we were able to avoid side effects such as muscle rigidity induced by a bolus injection of remifentanil $[14,15]$.

There have been many studies done on the effects of smoking on the cardiovascular system. According to McVeigh et al. [16], the resting heart rate was higher in smokers than in nonsmokers. They also reported that the systolic and diastolic pressures and the MAP were lower in smokers than those in nonsmokers. In a study on only women, Laxton et al. [6] asserted that heart rate of smokers immediately after intubation was significantly greater than that of nonsmokers. Yet Jee and
A

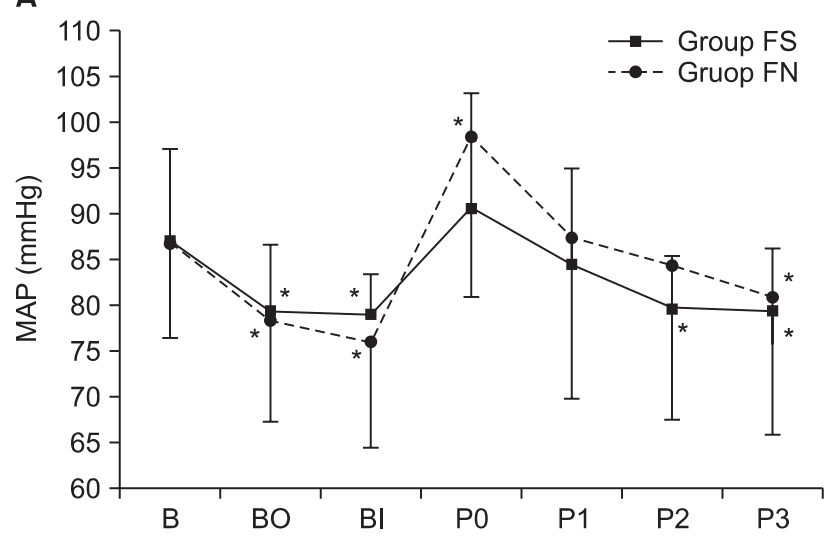

B

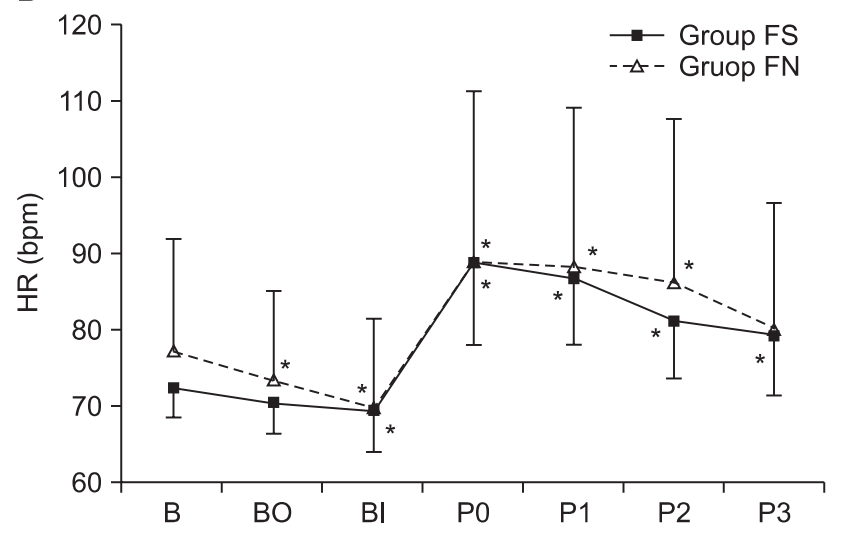

Fig. 2. Changes of the mean arterial pressure (MAP, A) and heart rate (HR, B) in women. The HRs during postintubation period were increased compared with baseline in each group $(\mathrm{P}<0.05)$, but there were no differences between the two groups. Group FS: female smokers, Group FN: female nonsmokers, B: baseline, BO: on unconsciousness, BI: just before intubation, P0: just after intubation, P1, 2, 3: 1, 2, 3 minutes after intubation, respectively. $* \mathrm{P}<0.05$ compared with baseline. 
Park [17] argued that the baseline blood pressure and heart rate are not different for smokers and nonsmokers. In fact, in a non-stimulated state, nicotine affects the sympathetic nervous system, it elevates the heart rate and it causes vasoconstriction. Smokers who abstained from smoking for a short period of time experience a reduction in the plasma catecholamine level, which reduces the heart rate and arterial blood pressure [18]. This current study showed no difference in the baseline heart rate or MAP between the smokers and nonsmokers. So our research findings were in accordance with the findings of Jee and Park [17]. But the difference in research findings among the different studies is construed to be due to the different characteristics of the patient subjects such as their age, their history of smoking and their history of abstinence from smoking.

Smoking elevates the blood pressure and the heart rate, but abstinence from smoking during a period of preparation for surgery shows various hemodynamic responses depending on the duration of abstinence and the patients age and gender. Further research needs to be done on this. Moreover, there is no study on the effect of the smoking period on the cardiovascular system, so this needs further research as well.

Smoking has a strong adrenergic agonistic effect, and so it increases the blood pressure, heart rate and systemic vascular resistance [19]. The change in heart rate is controlled by the autonomic nervous system. The effect the autonomic nervous system has on the sinus node is ever-changing due to internal and external factors. The regular change in the heart rate is called heart rate variability. Smoking is said to reduce such heart rate variability [20]. Such reductions are a serious risk factor for cardiac diseases $[21,22]$. Smokers are two times more as likely to suffer from coronary arterial diseases than are nonsmokers [23,24].

This study showed that there was a difference in the hemodynamic response to endotracheal intubation between male smokers and nonsmokers, while there was not such a difference in the female groups. Jee and Moon [25] reported that men have a longer sustained elevation of systolic blood pressure. It appears that the length of the blood pressure elevation is gender-based, so it is believed that gender also affects the change in hemodynamic responses. HinojosaLaborde et al. [26] reported that there is a gender difference in the control of the sympathetic nervous system. The control of the sympathetic nervous system in women is a bit more efficient than that in men. In this study, there was no difference in the endotracheal intubation-caused hemodynamic response in the women groups, regardless of whether they smoked or not. Perhaps this is because the efficient control of the sympathetic nervous system offsets the hemodynamic responses.

In conclusion, for men, there was a difference in the hemo- dynamic response to endotracheal intubation using remifentanil between the smokers and nonsmokers. However, for women, there was no such difference. There has been much controversy over the gender difference of the endotracheal intubation-caused hemodynamic change. For obtaining consistent results, more research should be performed with controlling for many factors.

\section{References}

1. Sikka PK. Basic pharmacologic principles. In: Basics of anesthesia. 5th ed. Edited by Stoelting RK, Miller RD: Philadelphia, Churchill Livinstone Elsevier. 2007, pp 41-2.

2. Shim MS, Kim JD, Choi HK, Yoo SB, Ryu SJ, Kim KH, et al. Optimal dose of remifentanil and propofol TCI for minimizing cardiovascular changes to tracheal intubation during total intravenous anesthesia. Korean J Anesthesiol 2008; 54: 389-94.

3. Lee SH, Han JI, Kim CH. Target-controlled infusion of remifentanil during propofol induction in hypertensive patients: Effects of three different remifentanil concentrations on hemodynamic changes. Korean J Anesthesiol 2007; 53: S12-8.

4. Yim EB, Lee KY, Han JI, Chung RK. Hemodynamic changes between different remifentanil administration methods during induction in the elderly. Korean J Anesthesiol 2007; 53: 714-9.

5. Lim EB, Baik HJ, Kim JH, Kim YJ. Heart rate variability during propofol-remifentanil TCI induction in diabetic patients. Korean J Anesthesiol 2007; 53: 180-7.

6. Laxton $\mathrm{CH}$, Milner Q, Murphy PJ. Haemodynamic changes after tracheal intubation in cigarette smokers compared with nonsmokers. Br J Anaesth 1999; 82: 442-3.

7. Cuvas O, Er A, Ikeda OC, Dikmen B, Basar H. Cigarette smoking and the haemodynamic response to tracheal intubation. Anaesthesia 2008; 63: 463-6.

8. Zhu BQ, Parmley WW. Hemodynamic and vascular effects of active and passive smoking. Am Heart J 1995; 130: 1270-5.

9. Derbyshire DR, Chmielewski A, Fell D, Vater M, Achola K, Smith G. Plasma catecholamine responses to tracheal intubation. Br J Anaesth 1983; 55: 855-60.

10. Prys-Roberts C, Greene LT, Meloche R, Foëx P. Studies of anaesthesia in relation to hypertension. II. Hemodynamic consequences of induction and endotracheal intubation. Br J Anaesth 1998; 80: 10622.

11. Kovac AL. Controlling the hemodynamic response to laryngoscopy and endotracheal intubation. J Clin Anesth 1996; 8: 63-79.

12. Chung F, Evans D. Low-dose fentanyl: haemodynamic response during induction and intubation in geriatric patients. Can Anaesth Soc J 1985; 32: 622-8.

13. Hall AP, Thompson JP, Leslie NA, Fox AJ, Kumar N, Rowbotham DJ. Comparison of different doses of remifentanil on the cardiovascular response to laryngoscopy and tracheal intubation. Br J Anaesth 2000; 84: 100-2.

14. Hogue CW Jr, Bowdle TA, O'Leary C, Duncalf D, Miguel R, Pitts M, et al. A multicenter evaluation of total intravenous anesthesia with remifentanil and propofol for elective inpatient surgery. Anesth Analg 1996; 83: 279-85. 
15. Philip BK, Scuderi PE, Chung F, Conahan TJ, Maurer W, Angel JJ, et al. Remifentanil compared with alfentanil for ambulatory surgery using total intravenous anesthesia. The remifentanil/alfentanil outpatient TIVA group. Anesth Analg 1997; 84: 515-21.

16. McVeigh GE, Morgan DJ, Finkelstein SM, Lemay LA, Cohn JN. Vascular abnormalities associated with long-term cigarette smoking identified by arterial waveform analysis. Am J Med 1997; 102: 227-31.

17. Jee DL, Park UK. Hemodynamic response of young smokers to induction and intubation. Korean J Anesthesiol 2006; 50: S14-8.

18. Roth GM, Shick RM. The cardiovascular effects of smoking with special reference to hypertension. Ann NY Acad Sci 1960; 90: 308-16.

19. Kobayashi F, Watanabe T, Akamatsu Y, Furui H, Tomita T, Ohashi R, et al. Acute effects of cigarette smoking on the heart rate variability of taxi drivers during work. Scand J Work Environ Health 2005; 31: 360-6.

20. Hemingway H, Shipley M, Brunner E, Britton A, Malik M, Marmot M. Does autonomic function link social position to coronary risk? The Whitehall II study. Circulation 2005; 111: 3071-7.

21. Tsuji H, Venditti FJ Jr, Manders ES, Evans JC, Larson MG, Feldman $\mathrm{CL}$, et al. Reduced heart rate variability and mortality risk in an elderly cohort. The Framingham Heart Study. Circulation 1994; 90: 878-83.

22. Dekker JM, Schouten EG, Klootwijk P, Pool J, Swenne CA, Kromhout D. Heart rate variability from short electrocardiographic recordings predicts mortality from all causes in middle-aged and elderly men. The Zutphen study. Am J Epidemiol 1997; 145: 899-908.

23. Jacobs DR Jr, Adachi H, Mulder I, Kromhout D, Menotti A, Nissinen A, et al. Cigarette smoking and mortality risk: twenty-five-year follow-up of the seven countries study. Arch Intern Med 1999; 159: 733-40.

24. Chun BY, Dobson AJ, Heller RF. Smoking and the incidence of coronary heart disease in an Australian population. Med J Aust 1993; 159: 508-12.

25. Jee D, Moon HL. Gender may affect the hemodynamic response to induction and intubation in young adults. J Clin Anesth 2004; 16: 563-7.

26. Hinojosa-Laborde C, Chapa I, Lange D, Haywood JR. Gender differences in sympathetic nervous system regulation. Clin Exp Pharmacol Physiol 1999; 26: 122-6. 